\title{
AVALIAÇÃO DA QUALIDADE DA ÁGUA E ESTADO TRÓFICO DO RIBEIRÃO DAS ABÓBORAS, EM RIO VERDE - GO, BRASIL
}

\author{
Wellmo dos Santos ALVES ${ }^{1}$; Leonardo Nazário Silva dos SANTOS ${ }^{1}$; Victor Souza \\ MEDEIROS $^{1}$; Davi Santiago AQUINO ${ }^{1}$; Wilker Alves MORAIS ${ }^{1}$; Bruno Botelho \\ SALEH $^{1}$; Vinícius Cruvinel PEREIRA ${ }^{2}$; Derick Martins Borges de MOURA ${ }^{3}$
}

(1) Instituto Federal de Educação, Ciência e Tecnologia Goiano - Campus Rio Verde, Rio Verde - GO; Rodovia Sul Goiana, Km 01, S/N - Zona Rural - CEP: 75901-970. Caixa Postal 66. Endereços Eletrônicos: wellmo.alves@ ifgoiano.edu.br; leonardo.santos@ifgoiano.edu.br; victor.s.medeiros@outlook.com; davi.aquino@ifgoiano.edu.br; wilker.alves.morais@gmail.com.; bruno.eloisa@brturbo.com.br.

(2) Secretaria Municipal de Desenvolvimento Econômico Sustentável de Rio Verde - GO; Rua Almiro de Moraes, 245 Centro - CEP: 75901-150. Endereço Eletrônico: viniciuscruvinel@ rioverdegoias.com.br.

(3) Universidade Federal de Goiás/Regional Jataí Unidade Riachuelo. Rua Riachuelo, 1530 - B. Samuel Graham, CEP 75800-000. Jataí - GO. Endereço eletrônico: derickmartins @ hotmail.com

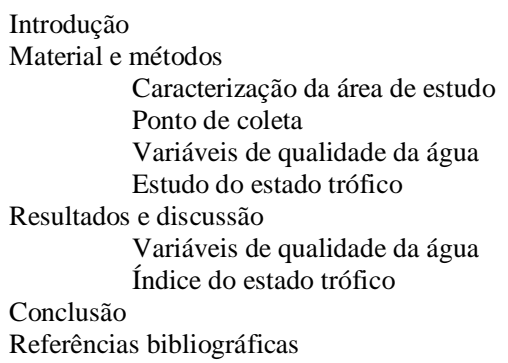

RESUMO - Este trabalho teve como objetivo avaliar a qualidade da água do Ribeirão das Abóboras, através da análise da temperatura, oxigênio dissolvido, condutividade elétrica, sólidos dissolvidos totais, potencial hidrogeniônico, turbidez, demanda química de oxigênio, alumínio, nitrato, fósforo total e do estudo de estado trófico, visando subsidiar ação de planejamento e política desta importante bacia produtora de água para a população de Rio Verde - GO (as campanhas de coleta tiveram periodicidade mensal entre junho de 2012 a janeiro de 2013), sendo seus valores comparados com limites estabelecidos pela Resolução CONAMA 357/05 para corpos de água doce classe 2. Os índices obtidos de estado trófico foram comparados com a classificação de Lamparelli (2004) modificado. Os valores médios estiveram dentro dos limites preconizados pela Resolução supracitada, exceto quanto ao teor de fósforo em todas as amostras. Os valores elevados de fósforo total refletiram em índices altos de estado trófico, ou seja, de junho a dezembro a água do ribeirão em questão se encontra no estado eutrófico e em janeiro supereutrófico, sugerindo que ações devem ser tomadas para minimizar o aporte deste nutriente a fim de evitar a possível eutrofização desse curso hídrico.

Palavras-chave: gestão de recursos hídricos, Resolução CONAMA 357/05, variáveis físico-químicas.

ABSTRACT - This paper had as an objective evaluating the quality of the water of Ribeirão das Abóboras, through the temperature analysis, dissolved oxygen, electric conductivity, total dissolved solid, hydrogenionic potential, turbidity, Chemical Oxygen Demand, aluminum, nitrate, total phosphorus and the study of the trophic state in order to subsidize a planning and political action of this important basin which produces water for the population of Rio Verde - GO, (the collection campaigns had a monthly period between June 2012 to January 2013), and their values were compared to the limits established by CONAMA 357/05 Resolution for Class 2 fresh water bodies. The indexes obtained in the trophic state were compared to the modified Lamparelli classification (2004). It was possible to notice that the average values were within the recommended limits by the Resolution mentioned before, except concerning the phosphorus content in all samples. The high values of total phosphorus reflected in high indexes of trophic state, in other words, from June to December the water of the studied stream was found in the eutrophic state and in January in the hypereutrophic state, suggesting that actions must be taken to minimize the contribution of this nutrient in the stream in order to avoid a possible eutrophication of this water course.

Keywords: hydrous resources management, CONAMA 357/05 Resolution, physicochemical variables.

\section{INTRODUÇÃO}

Historicamente, observa-se que a água é um recurso vital para a existência do ser humano, tanto para abastecimento quanto para o desenvolvimento de atividades agrícolas e industriais. Várias civilizações desenvolveram-se econômica e socialmente em regiões onde a água era um recurso abundante.

O Brasil é um país dotado de grandes reservas hídricas superficiais e 
biodiversidade aquática, mas com uma distribuição desigual entre as diversas regiões hidrográficas (ANA, 2015). Além da distribuição desigual dos recursos hídricos no território brasileiro, Silva et al. (2008) relatam que a poluição compromete este recurso nas cidades, pelo seu crescente consumo, contaminação por esgotos domésticos, ocupação das margens dos arroios e rios por habitações e, na zona rural, pela exploração exagerada e destruição da mata ciliar, originando espaço ocupado com atividades agrícolas e de pecuária.

No território brasileiro, a Lei Federal $n^{\circ}$ 9.433 de 8 de janeiro de 1997 institui a bacia hidrográfica como unidade territorial para aplicação da Política Nacional de Recursos Hídricos (Brasil, 1997), onde podem ser encontradas transformações causadas espontaneamente ou por ações humanas.

A paisagem das microbacias vem sendo modificada ao longo dos anos devido à falta de um planejamento conservacionista, que pode ser caracterizada pelo mau uso e ocupação dos solos (Torres \& Fabian, 2006) e pela introdução de grande variedade e quantidade de poluentes. Estes fatos promovem um desequilíbrio no ecossistema aquático e, consequentemente, deterioração das fontes de água. Diante disso, é importante que sejam feitos levantamentos e diagnósticos dos passivos ambientais que possam resultar no aporte destes poluentes às fontes hídricas.

O município de Rio Verde - GO, apresenta uma agricultura intensiva, um parque agroindustrial diversificado, além de uma população urbana crescente, consequentemente, danos ambientais são causados às bacias hidrográficas que drenam o município (Rodrigues, 2008). Em 2010 o município possuía 176.424 habitantes (IBGE, 2010) e em 2014 passou a ter uma população estimada de 202.221 habitantes (IBGE, 2014), aumento de 14,62\%.

O Ribeirão das Abóboras ainda não foi analisado com o propósito de fazer o seu enquadramento, de acordo com a Resolução do Conselho Nacional do Meio Ambiente (CONAMA) no 357 de 17 de março de 2005 (alterada pela Resolução 410/2009 e pela 430/2011), que dispõe sobre a classificação dos corpos de água, diretrizes ambientais para o seu enquadramento e dá outras providências. Entretanto, segundo essa resolução, em seu artigo 42, enquanto não aprovado o enquadramento de um corpo de água doce, este será considerado como classe 2 , exceto se as condições de qualidade atuais forem melhores, o que determinará a aplicação da classe mais rigorosa correspondente (Brasil, 2005).

De todo o volume da água distribuído à população urbana de Rio Verde - GO, pelo sistema de abastecimento público, em torno de $83 \%$ é proveniente da captação de mananciais superficiais, e $17 \%$ restantes correspondem à captação subterrânea de poços que explotam água dos aquíferos Bauru e Serra Geral. O Ribeirão das Abóboras é a principal fonte de água que abastece a população urbana rio-verdense $\left(1.152 \mathrm{~m}^{3} \mathrm{~h}^{-1}\right)$, além de fornecer água para uso nos processos industriais $\mathrm{e}$ abastecimento das propriedades rurais (Garcia et al., 2007).

Diante do exposto, objetivou-se avaliar a qualidade e o estado trófico da água do Ribeirão das Abóboras em Rio Verde - GO.

\section{MATERIAL E MÉTODOS}

\section{Caracterização da área de estudo}

O Ribeirão das Abóboras está localizado na região central do município de Rio Verde - GO (Figura 1). A nascente localiza-se nas coordenadas $17^{\circ} 45^{\prime} 4,927$ "S, altitude de $853 \mathrm{~m}$, e seu exutório na margem esquerda do Rio São Tomaz, nas coordenadas $50^{\circ} 55^{\prime} 0,677^{\prime \prime} \mathrm{W}$ e $17^{\circ} 54^{\prime} 43,223$ "S, em uma altitude de $640 \mathrm{~m}$. 

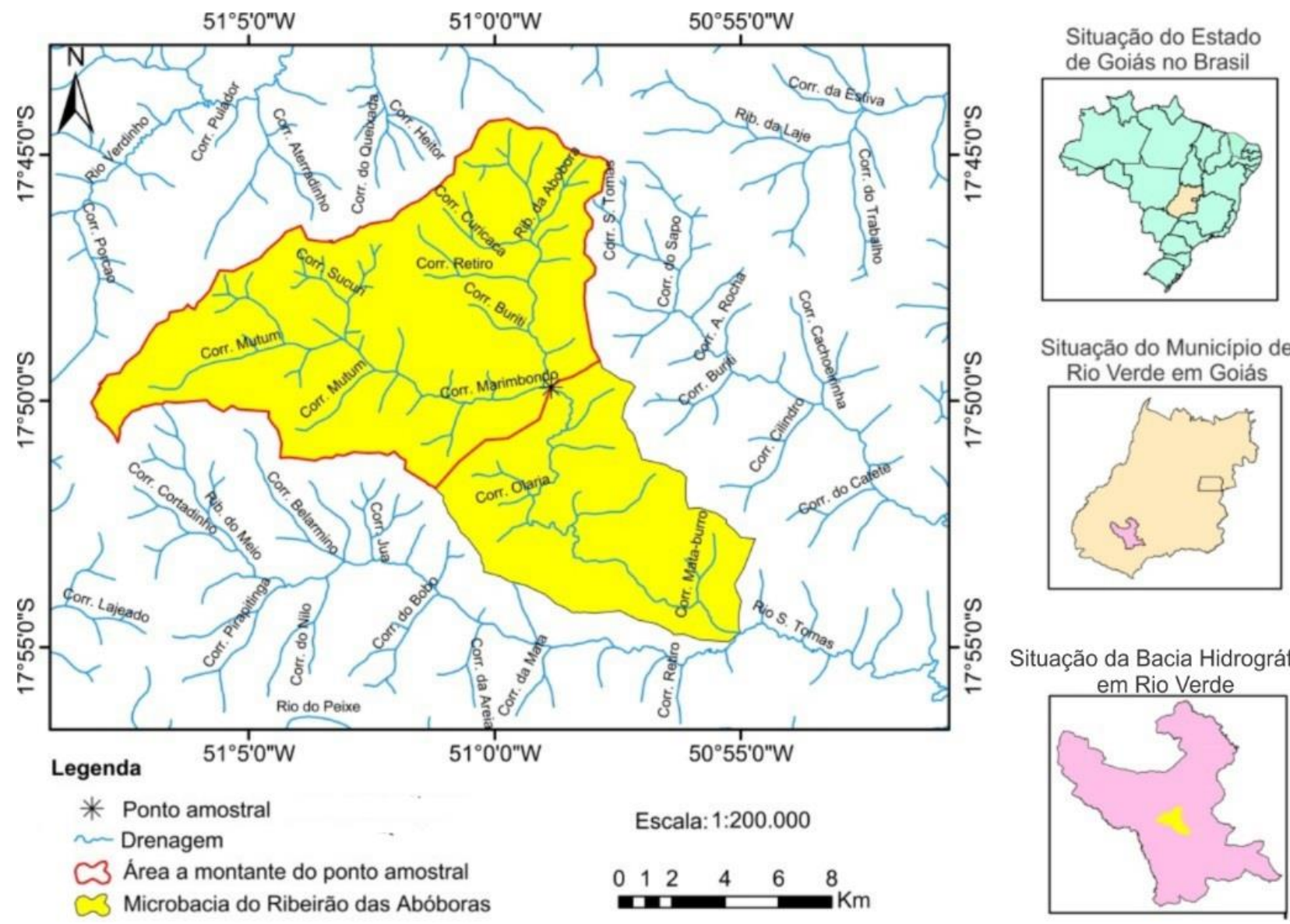

Escala: 1:200.000

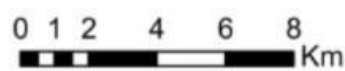

Situação da Bacia Hidrográfica

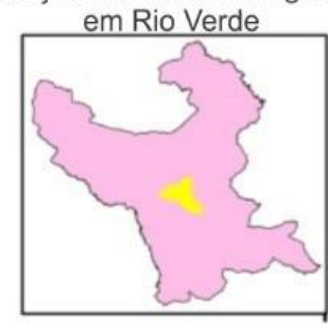

Figura 1. Mapa de localização da bacia hidrográfica do Ribeirão das Abóboras,

Rio Verde - GO, processado no Software SIG ArcGIS 10.1.

Fonte: Elaborado por Alves, W. S. (2016) a partir de bases de dados geográficos disponibilizadas pelo SIEG

(2016).

No intuito de melhor caracterizar a área da bacia a montante do ponto amostral, foi realizada a caracterização do uso e cobertura da terra, geologia, geomorfologia e pedologia, com uso do software ArcGIS $10.1^{\circledR}$ licenciado para o Laboratório de Geoprocessamento da Universidade Federal de Goiás/Regional de Jataí. Os mapas foram elaborados nas coordenadas geográficas, utilizando Datum SIRGAS 2000.

O uso e cobertura da terra foi realizado a partir de uma imagem de 2013 do Sensor OLI acoplado ao satélite Landsat 8, com resolução espacial de $30 \times 30 \mathrm{~m}$, gerada pela National Aeronautics and Space Administration (NASA) e disponibilizada pelo Serviço Geológico dos Estados Unidos (USGS, 2016), com aplicação da ferramenta
Image Classification do software ArcGIS $10.1^{\circledR}$. A legenda prévia foi assim definida: agricultura, pastagem, matas/Cerrado, eucalipto, setor industrial, rodovia BR-060, granjas e área urbanizada. Com as amostras das classes previamente estabelecidas, foi adotado o Google Earth Pro e realizadas visitas de campo com a finalidade de verificar, atualizar e validar a legenda preliminar adotada. Em seguida, foi realizado o cálculo das áreas de cada classe de uso e cobertura vegetal. A base metodológica seguida foi o Manual Técnico de Uso da Terra (Brasil, 2013). Os resultados obtidos para o uso e cobertura vegetal da terra estão apresentados na Tabela 1 . 
Tabela 1. Uso e cobertura do solo na área de contribuição do ponto amostral.

\begin{tabular}{ccc}
\hline Uso e cobertura & Área $\left(\mathrm{km}^{2}\right)$ & Em \% \\
\hline Agricultura & 62,42 & 46,46 \\
Pastagem & 33,37 & 24,84 \\
Matas/Cerrado & 29,50 & 21,96 \\
Eucalipto & 6,14 & 4,57 \\
Setor industrial & 1,62 & 1,20 \\
Granjas & 0,60 & 0,45 \\
Rodovia pavimentada & 0,46 & 0,34 \\
Água & 0,24 & 0,18 \\
Área total & 134,35 & 100,00 \\
\hline
\end{tabular}

A área de $134,35 \mathrm{~km}^{2}$ à montante do ponto amostral, conforme Tabela 1, apresenta um percentual de $46,46 \%(62,42$ $\mathrm{km}^{2}$ ) ocupado por lavouras anuais (soja, milho, sorgo, entre outras culturas em menor escala), $24,84 \%\left(33,37 \mathrm{~km}^{2}\right)$ por pastagens, $21,96 \%\left(29,50 \mathrm{~km}^{2}\right)$ por matas/Cerrado, $4,57 \%\left(6,14 \mathrm{~km}^{2}\right)$ por cultivo de eucalipto, $1,20 \%\left(1,62 \mathrm{~km}^{2}\right)$ por instalação de um setor industrial (fábrica de ração, frigorífico, indústrias alimentícias entre outras), $0,45 \%$ $\left(0,60 \mathrm{~km}^{2}\right)$ por 17 granjas de grande porte para a criação de aves e suínos, $0,34 \%(0,46$ $\left.\mathrm{km}^{2}\right)$ por rodovia pavimentada e $0,18 \%(0,24$ $\mathrm{km}^{2}$ ) por corpos hídricos. A espacialização do uso e cobertura vegetal da terra pode ser observada na Figura 2. Logo, é uma bacia hidrográfica com uso predominantemente agrícola. Destacam-se na bacia o cultivo de soja e milho safrinha, sendo o plantio da soja realizado de outubro a novembro e do milho safrinha de janeiro a abril.

Considerando a área de contribuição até o ponto amostral, todos os cursos hídricos somam 95,62 km, sendo que o curso principal equivale a $12,66 \mathrm{~km}$ e apresenta declividade de $0,012 \mathrm{~m} \mathrm{~m}^{-1}$.

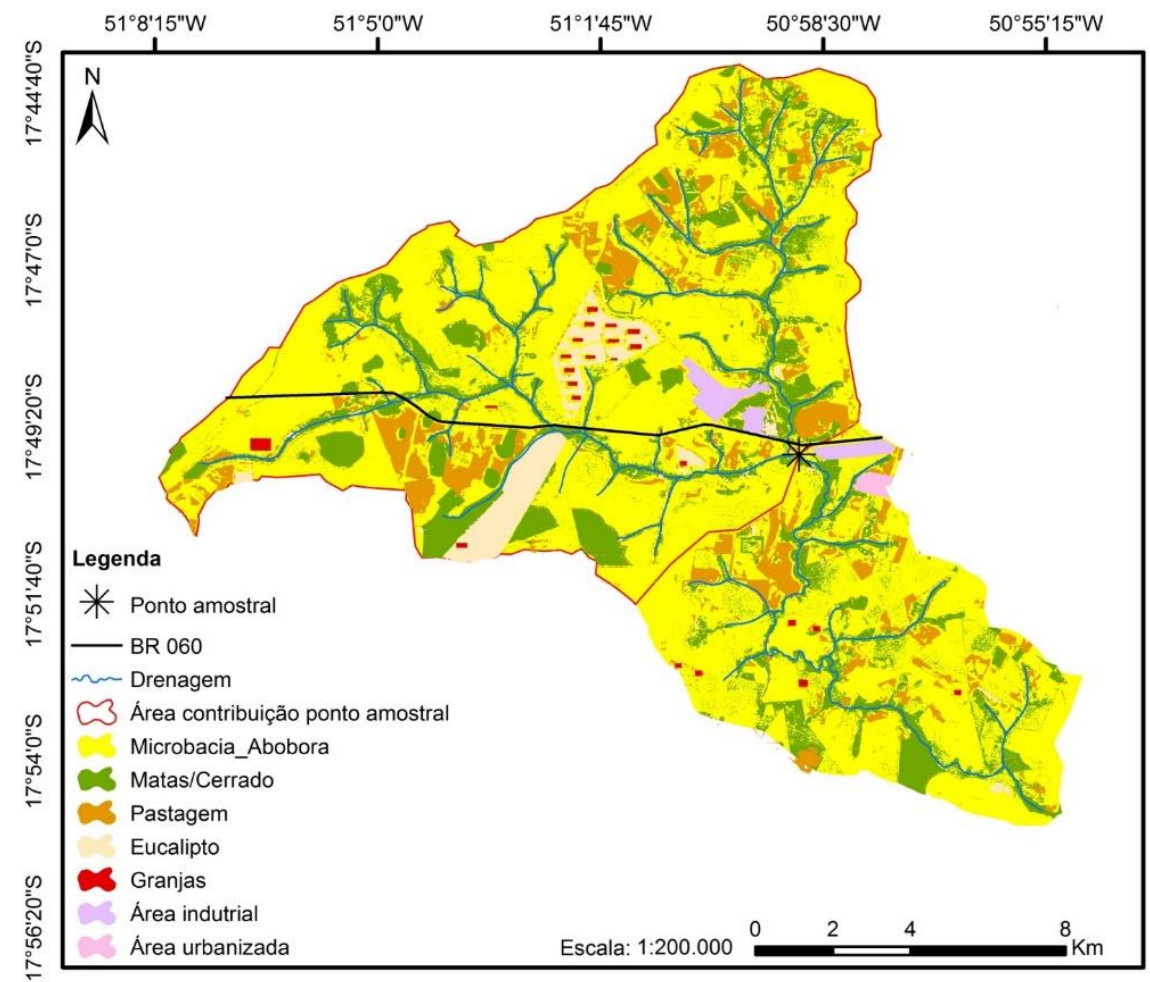

Figura 2. Mapa de uso e ocupação do solo da bacia hidrográfica do Ribeirão das Abóboras.

Fonte: Elaborado por Alves, W. S. (2016) a partir de bases de dados geográficos disponibilizadas pelo SIEG (2016) e de imagem de 2013 do satélite Landsat 8/Sensor OLI disponibilizada pelo USGS (2016). 
A caracterização da geologia da bacia foi realizada a partir do Mapa Geológico do Estado de Goiás e Distrito Federal (escala 1:500.000), da geomorfologia a partir do Mapa Geomorfológico do Estado de Goiás e Distrito Federal (escala 1:500.000), e da pedologia a partir do Mapa de Solos do Plano Diretor da Bacia do Rio Paranaíba (escala 1:250.000). Todas as bases de dados geográficos foram disponibilizadas pelo Sistema Estadual de Geoinformação de Goiás (SIEG, 2016).
A área de estudo está inserida no Planalto Setentrional da Bacia Sedimentar do Paraná. As rochas, que afloram na bacia hidrográfica, são de idades entre o Neogeno e o Cretáceo, rochas sedimentares do Grupo Bauru - Formação Vale do Rio do Peixe $(54,99 \%)$, coberturas detríticas indiferenciadas $(32,69 \%)$ e rochas ígneas do Grupo São Bento - Formação Serra Geral (12,32\%), conforme Tabela 2 e Figura 3a (SIEG, 2016).

Tabela 2. Classes de geologia da área de contribuição do ponto amostral.

\begin{tabular}{lccc}
\hline \multicolumn{1}{c}{ Classe } & Litotipo & $\mathrm{Km}^{2}$ & $\%$ \\
\hline Grupo Bauru - Formação Vale do Rio do Peixe & Arenito, argilito arenoso. & 73,88 & 54,99 \\
Coberturas detríticas indiferenciadas & Depósitos de areia, cascalho e & 43,92 & 32,69 \\
Grupo São Bento - Formação Serra Geral & argila. & 16,55 & 12,32 \\
\hline \multicolumn{1}{c}{ Total } & Basalto, basalto-andesito. & 134,35 & 100 \\
\hline
\end{tabular}

Fonte: Elaborado pelos autores a partir do Mapa Geológico de Goiás disponibilizado pelo SIEG (2016).

A área apresenta predominância $(81,80 \%)$ da superfície regional de aplainamento IIIB com cotas entre 650 e 750 $\mathrm{m}$, dissecação média associada a relevos tabulares (SRAIIIB-RT); em menor percentual
$(18,20 \%)$ superfície regional de aplainamento IIB com cotas entre 800 e 1000 m, dissecação média associada a relevos tabulares (SRAIIBRT), Tabela 3 e Figura 3b.

Tabela 3. Classes de geomorfologia da área de contribuição do ponto amostral.

\begin{tabular}{ccc}
\hline Classe & $\mathrm{Km}^{2}$ & $\%$ \\
\hline SRAIIIB-RT & 109,90 & 81,80 \\
SRAIIB-RT & 24,45 & 18,20 \\
\hline Total & 134,35 & 100 \\
\hline
\end{tabular}

Fonte: Elaborado pelos autores a partir do Mapa Geomorfológico de Goiás disponibilizado pelo SIEG (2016).

(a)

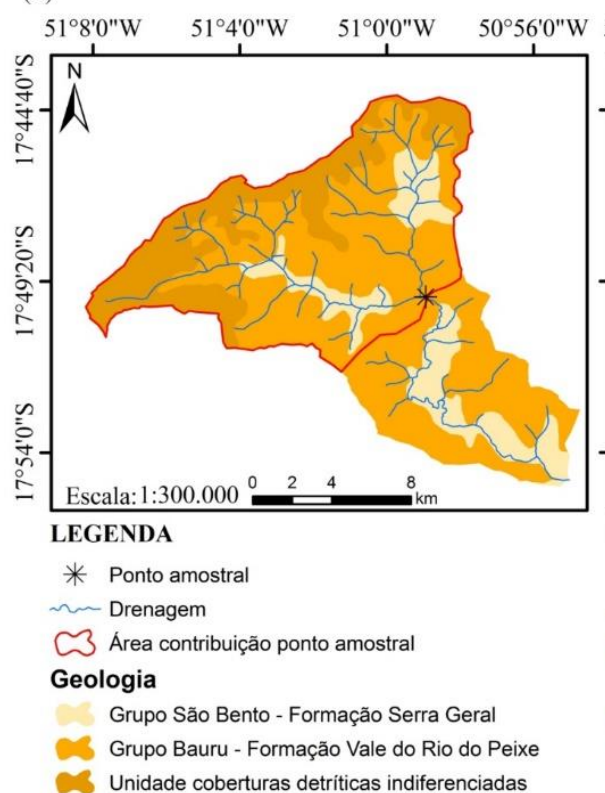

(b)

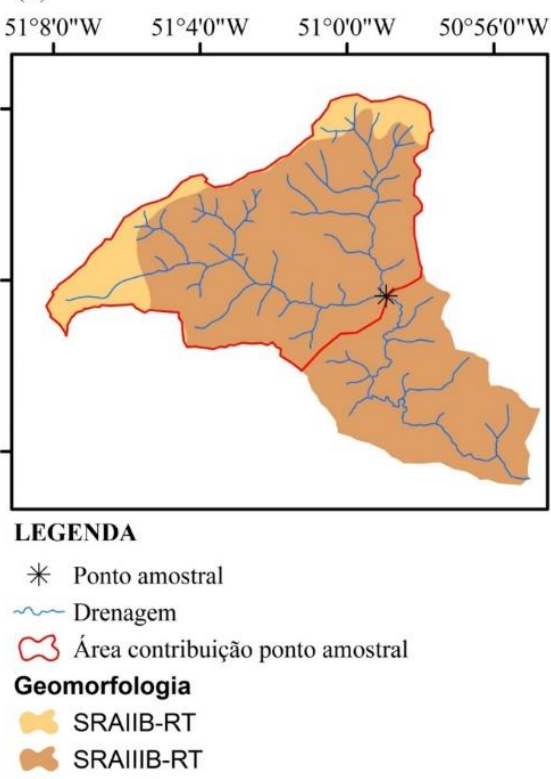

Figura 3. Mapa geológico e geomorfológico da bacia do Ribeirão das Abóboras.

Fonte: Elaborado por Alves, W. S. (2016) a partir dos Mapas Geológico (a) e Geomorfológico (b) de Goiás e Distrito Federal disponibilizados pelo SIEG (2016). 
A área apresenta duas ordens de solo: Latossolo e Argissolo, sendo Latossolo Vermelho Distrófico (LVd) em maior percentual $(93,47 \%)$ e Argissolo Vermelho Distrófico (PVd) em menor extensão (6,53\%), Tabela 4 e Figura 4. Os Latossolos são ácidos e pobres em nutrientes, necessitando de correção da acidez e adubação para o cultivo agrícola. Os adubos químicos aplicados em maior quantidade são os que apresentam em sua composição nitrogênio, fósforo e potássio.

Tabela 4. Classes de solos da área de contribuição do ponto amostral.

\begin{tabular}{ccc}
\hline Classe & $\mathrm{Km}^{2}$ & $\%$ \\
\hline LVd & 125,58 & 93,47 \\
PVd & 8,77 & 6,53 \\
\hline Total & 134,35 & 100 \\
\hline
\end{tabular}

Fonte: Adaptado pelos autores do Mapa de Solos do Plano Diretor da Bacia do Rio Paranaíba disponibilizado pelo SIEG (2016).

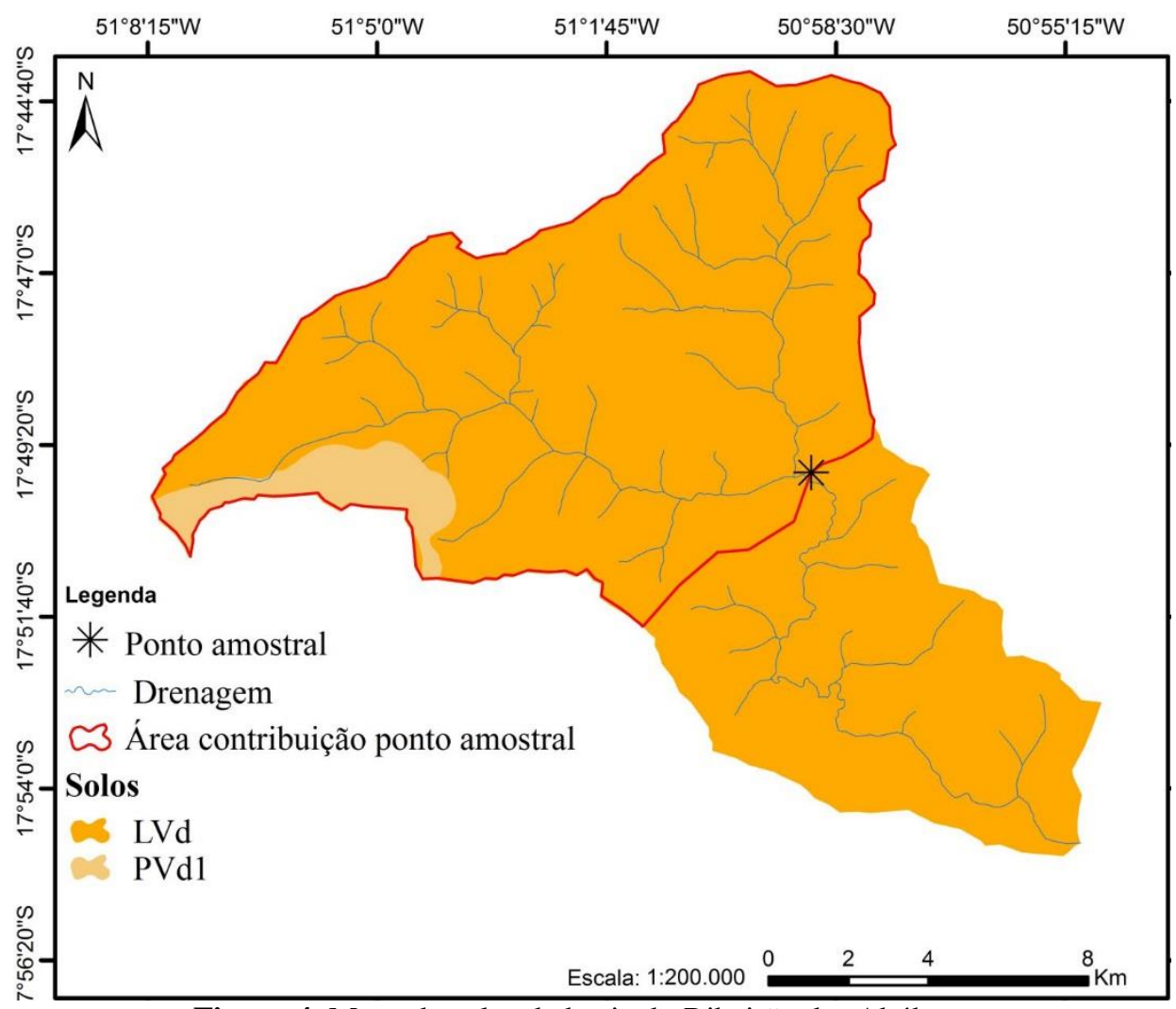

Figura 4. Mapa de solos da bacia do Ribeirão das Abóboras.

Fonte: Elaborado por Alves, W. S. (2016) a partir do Mapa de Solos de Goiás e Distrito Federal disponibilizado pelo SIEG (2016).

Segundo a classificação de Köppen-Geiger, o clima da região se enquadra no tipo AW, caracterizado por climas úmidos tropicais, com duas estações bem definidas: seca no inverno e úmida no verão (Peel et al., 2007). Rio Verde apresenta duas estações bem definidas: uma seca (de maio a outubro) e outra chuvosa (novembro a abril), sendo mesotérmico úmido, com temperaturas amenas durante o inverno e calor no verão. Nas estações outono-inverno são registradas as temperaturas mínimas, $6{ }^{\circ} \mathrm{C}$ à $15{ }^{\circ} \mathrm{C}$, sendo a temperatura média anual entre $20^{\circ} \mathrm{C}$ e $25^{\circ} \mathrm{C}$ (Ferreira, 2010).

Conforme pode ser observado na Figura 5, os meses com maior precipitação são de janeiro a abril e de outubro a dezembro, sendo de maio a agosto o período sem ou com pouca ocorrência de chuva (BDMEP, 2014). 


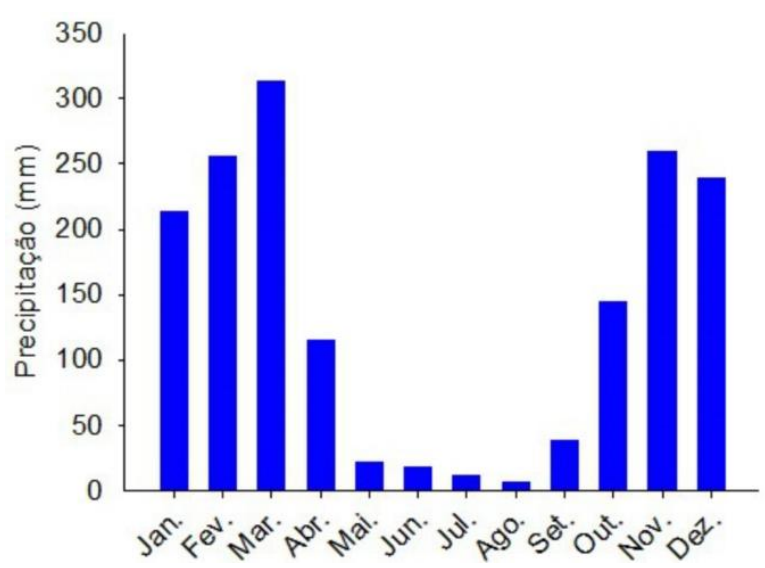

Figura 5. Gráfico de precipitação total mensal média de janeiro de 2004 a dezembro de 2014, em Rio Verde - GO. Fonte: BDMEP (2014).

O estudo, incluindo coletas e análises, foi realizado entre junho de 2012 a janeiro de 2013, exceto julho e agosto. As precipitações totais mensais nesse período foram de: 18,7 $\mathrm{mm}$, em junho; 1,4 mm, em julho; sem ocorrência de precipitação em agosto; $96,5 \mathrm{~mm}$, em setembro; $52,9 \mathrm{~mm}$, em outubro; $254,8 \mathrm{~mm}$, em novembro; $138,6 \mathrm{~mm}$, em dezembro; e 29,6 $\mathrm{mm}$, em janeiro (BDMEP, 2014).

\section{Ponto de coleta}

Objetivando identificar a qualidade da água utilizada no abastecimento da população rioverdense, a definição do ponto de amostragem ocorreu em função das características do corpo d'água, da natureza das cargas poluidoras (despejos industriais, águas de drenagem agrícola e instalações de granjas) e devido à sua proximidade com o ponto de captação para abastecimento público (30 m a montante), sendo realizado a $705 \mathrm{~m}$ de altitude nas coordenadas $50^{\circ} 58^{\prime} 34,914^{\prime \prime} \mathrm{W}$ e $17^{\circ} 50^{\prime} 27,016^{\prime \prime} \mathrm{S}$ (Figura 1, 2, 3 e 4).

\section{Variáveis de qualidade da água}

As coletas e a preservação das amostras seguiram as exigências da Resolução 724/2011 da Agência Nacional de Águas (Brasil, 2011).

No ponto de coleta foram determinados: temperatura, em ${ }^{\circ} \mathrm{C}$, e oxigênio dissolvido (OD), $\mathrm{mg} \mathrm{L}^{-1}$, utilizando um oxímetro modelo 55-12 FT; condutividade elétrica (CE), $\mu \mathrm{S} \mathrm{cm}^{-1}$, e sólidos dissolvidos totais (SDT), $\mathrm{mg} \mathrm{L}^{-1}$, em um equipamento portátil modelo Sension5; $\mathrm{pH}$, com um pHmetro portátil modelo PG1400. Os equipamentos foram devidamente calibrados conforme procedimentos descritos pelos fabricantes.
As amostras foram acondicionadas em caixa térmica com gelo e levadas diretamente para o Laboratório de Águas e Efluentes do Instituto Federal Goiano - Campus Rio Verde, onde foram analisadas as variáveis: turbidez, em UNT, com turbidímetro modelo 2100P; demanda química de oxigênio (DQO), alumínio $\left(\mathrm{Al}^{3+}\right)$, nitrato $\left(\mathrm{NO}_{3}{ }^{-}\right)$e fósforo total (FT), todas em $\mathrm{mg} \mathrm{L} \mathrm{L}^{-1}$, por espectrofotometria em um aparelho modelo DR 5000.

Todas as análises foram realizadas em triplicata e os métodos analíticos seguiram $o$ Standart Methods for Examination of Water and Wastewater da AWWA (America Water Works Association) (APHA, 2005).

Os valores obtidos foram submetidos aos estudos do desvio padrão e as médias de cada variável foram comparadas com os limites estabelecidos pela Resolução CONAMA 357/2005 (Brasil, 2005) para corpos de água doce classe 2 .

\section{Estudo do estado trófico}

Através dos resultados obtidos para fósforo total, foi realizado o estudo do índice de estado trófico (IET), estabelecido para ambientes lóticos, segundo a Equação 1 proposta por Lamparelli (2004):

$$
\operatorname{IET}(\mathrm{PT})=10 \times(6-((0.42-0.36 \times(\ln \mathrm{PT})) / \ln 2))-20
$$

Onde: PT é a concentração de fósforo total medida à superfície da água, em $\mu \mathrm{g} \mathrm{L}^{-1}$; e ln é o logaritmo natural.

Os resultados obtidos para o IET foram comparados com os valores para as diferentes categorias de estado trófico apresentados na Tabela 5. 
Tabela 5. Classificação do Estado Trófico para rios segundo índice proposto por Lamparelli (2004).

\begin{tabular}{cc}
\hline Categoria & Ponderação \\
(Estado Trófico) & IET $\leq 47$ \\
Ultraoligotrófico & $47<$ IET $\leq 52$ \\
Oligotrófico & $52<$ IET $\leq 59$ \\
Mesotrófico & $59<$ IET $\leq 63$ \\
Eutrófico & $63<$ IET $\leq 67$ \\
Supereutrófico & IET $>67$ \\
\hline
\end{tabular}

\section{RESULTADOS E DISCUSSÃO}

\section{Variáveis de qualidade da água}

Na Tabela 6 estão apresentados os valores obtidos para as variáveis analisadas e para os índices do estado trófico do Ribeirão das Abóboras, Rio Verde - GO.

Tabela 6. Valores mínimos e máximos e a média aritmética com seu respectivo desvio padrão das variáveis físicoquímicos e do índice do estado trófico obtidos durante o período de estudo e os valores mínimos e máximos estabelecidos pela Resolução CONAMA 357/05 para água doce classe 2.

\begin{tabular}{|c|c|c|c|c|c|}
\hline \multirow[t]{2}{*}{ Variáveis } & \multicolumn{3}{|c|}{ Valores obtidos } & \multicolumn{2}{|c|}{$\begin{array}{l}\text { Resolução CONAMA } \\
357 / 05\end{array}$} \\
\hline & Mín. & Máx. & Méd. e DP & Mín. & Máx. \\
\hline $\mathrm{T}\left({ }^{\circ} \mathrm{C}\right)$ & 20,53 & 23,90 & $22,56 \pm 1,16$ & - & - \\
\hline $\mathrm{OD}\left(\mathrm{mg} \mathrm{L}^{-1}\right)$ & 6,30 & 7,97 & $7,34 \pm 0,52$ & 5 & - \\
\hline $\mathrm{CE}\left(\mu \mathrm{S} \mathrm{cm}^{-1}\right)$ & 32,90 & 47,63 & $40,64 \pm 5,58$ & - & - \\
\hline $\operatorname{SDT}\left(\mathrm{mg} \mathrm{L}^{-1}\right)$ & 15,20 & 22,5 & $18,94 \pm 2,57$ & - & 500 \\
\hline $\mathrm{pH}$ & 6,60 & 7,81 & $7,34 \pm 0,51$ & 6 & 9 \\
\hline Turbidez (UNT*) & 7,85 & 57,80 & $24,93 \pm 6,31$ & - & 100 \\
\hline DQO $\left(\mathrm{mg} \mathrm{L}^{-1}\right)$ & 2,57 & 6,83 & $4,38 \pm 1,48$ & - & - \\
\hline $\mathrm{NO}_{3}^{-}\left(\mathrm{mg} \mathrm{L}^{-1}\right)$ & 0,21 & 2,35 & $1,2 \pm 0,71$ & - & 10 \\
\hline $\mathrm{Al}^{3+}\left(\mathrm{mg} \mathrm{L}^{-1}\right)$ & 0,02 & 0,08 & $0,05 \pm 0,02$ & - & 0,1 \\
\hline $\mathrm{FT}\left(\mathrm{mg} \mathrm{L}^{-1}\right)$ & 0,15 & 0,36 & $0,23 \pm 0,07$ & - & 0,1 \\
\hline $\mathrm{FT}\left(\mathrm{mg} \mathrm{m}^{-3}\right)$ & 150 & 360 & $230 \pm 70$ & - & 100 \\
\hline
\end{tabular}

*Unidade nefelométrica de turbidez.

Na Resolução CONAMA 357/05 não há limite para temperatura. No entanto, conforme Zumach (2003), esta é uma variável que desempenha um papel importante de controle no meio aquático, condicionando as influências de uma série de variáveis físico-químicas.

No período experimental, a temperatura da água variou de 20,53 a $23,90{ }^{\circ} \mathrm{C}$, sendo observadas temperaturas mais altas nos meses de novembro $\left(23,43{ }^{\circ} \mathrm{C}\right)$ e dezembro $\left(23,90^{\circ} \mathrm{C}\right)$ de 2012 e janeiro $\left(23,41{ }^{\circ} \mathrm{C}\right.$ ) de 2013 (Figura $6 a)$.

As variações de temperatura da água são decorrentes do regime climático. Dessa forma, os corpos hídricos apresentam variações sazonais e diurnas da temperatura superficial, bem como estratificação vertical, efeito resultante da ação de diversos fatores, dentre eles: latitude, altitude, estação do ano, período do dia, taxa de fluxo e profundidade do corpo hídrico (Tundisi \& Matsumura-Tundisi, 2008; Esteves, 2011).

Analisando a bacia do Rio Claro (Jataí $\mathrm{GO}$ ), que possui atividade predominantemente agrícola, Lima \& Santos (2012) observaram valores de temperatura da água variando de 22,60 a $23,30{ }^{\circ} \mathrm{C}$, no período seco, e de 24,70 a $26,80{ }^{\circ} \mathrm{C}$, no período chuvoso. Os autores afirmam que a variação diária de temperatura é devido aos horários das amostragens. Nos pontos com as menores médias, as amostras foram coletadas no período da manhã, com menor incidência da radiação solar. Já nos pontos com as maiores médias, as amostras foram coletadas no período da tarde, com maior incidência da radiação solar.

Nota-se na Figura 2 que as margens do Ribeirão das Abóboras encontram-se protegidas por área de preservação permanente (mata ciliar e de galeria). Segundo Rocha et al. (2014), o 
sombreamento do curso d'água deve ser levado em consideração para quantificação da temperatura da água, já que a redução da luminosidade ameniza consideravelmente o aquecimento da água superficial.

O oxigênio dissolvido é de fundamental importância na manutenção da vida aquática e da qualidade da água (Pinto et al., 2010). Os cursos de água (riachos, córregos, ribeirões e rios), em condições naturais, apresentam alto teor de OD, com tendência à saturação, dependendo da temperatura e pressão atmosférica (Tundisi \& Matsumura-Tundisi, 2008; Esteves, 2011; CETESB, 2016).

Em todo o período de estudo, o valor mínimo obtido de OD foi de $6,30 \mathrm{mg} \mathrm{L}^{-1}$ e o máximo de 7,97 $\mathrm{mg} \mathrm{L}^{-1}$ (Tabela 6), sendo que o mês de junho apresentou a menor média (Figura 6b). Os resultados atenderam ao limite mínimo estabelecido pela Resolução CONAMA $357 / 05$ de $5,00 \mathrm{mg} \mathrm{L}^{-1}$ para corpos de água doce classe 2 .

Valores de OD dentro do exigido pelo CONAMA para água doce classe 2 também

(a)

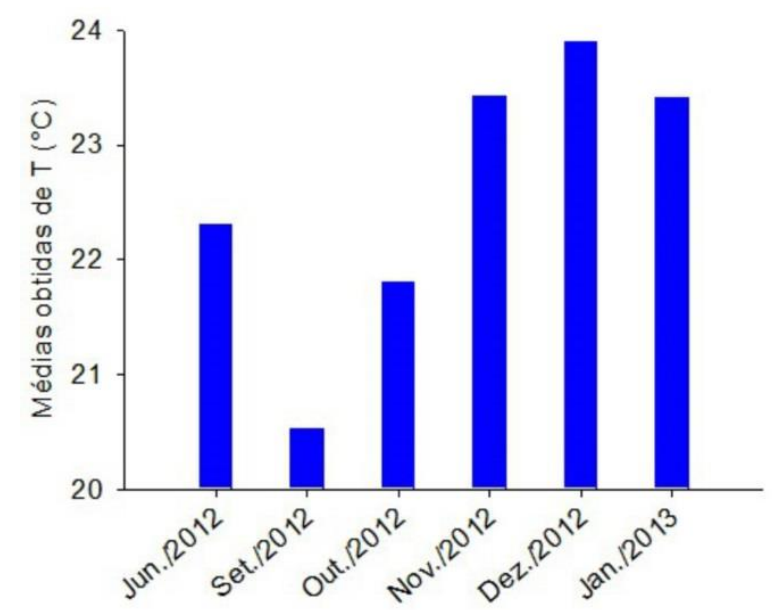

Figura 6. Gráfico com os valores mensais de temperatura (a) e oxigênio dissolvido (b) obtidos das águas do Ribeirão das Abóboras durante o período de ensaio.

Não há valores pré-determinados de CE para enquadramento de corpos hídricos superficiais, mas esta é uma variável de grande importância adotada em conjunto com outras nos estudos de qualidade de águas. Segundo Couto et al. (2006), nos ambientes aquáticos, a CE com valor até $100 \mu \mathrm{S} \mathrm{cm}^{-1}$ reflete as condições de águas de boa qualidade, e acima desse valor são águas inadequadas ao consumo humano. Segundo Esteves (2011) e CETESB (2016), a foram encontrados por Pimenta et al. (2009) na avaliação da qualidade das águas da bacia do rio São Tomaz, em Rio Verde - GO, predominantemente rural. Após realizar as análises no período chuvoso, os autores observaram concentração de OD variando entre 5 e $8 \mathrm{mg} \mathrm{L}^{-1}$. Por outro lado, baixos valores de OD $\left(0,30\right.$ a $\left.1,90 \mathrm{mg} \mathrm{L}^{-1}\right)$ foram observados por Medeiros et al. (2009) no diagnóstico da qualidade da água da microbacia do Córrego Recanto, em Americana - SP, situada em área urbana com lançamentos de esgoto bruto (matéria orgânica).

Vasco et al. (2011) ao realizar a avaliação da qualidade da água na sub-bacia do rio Poxim, no Estado de Sergipe, que apresenta áreas urbanas, agrícolas e industriais, observaram baixas concentrações de OD, médias variando de 2,10 a $4,70 \mathrm{mg} \mathrm{L}^{-1}$ no período chuvoso, e 4,30 a 5,60 $\mathrm{mg} \mathrm{L}^{-1}$ no período seco. Os autores atribuíram a baixa oxigenação das águas devido a presença da matéria orgânica (esgotos) e da própria característica física dos trechos dos rios.

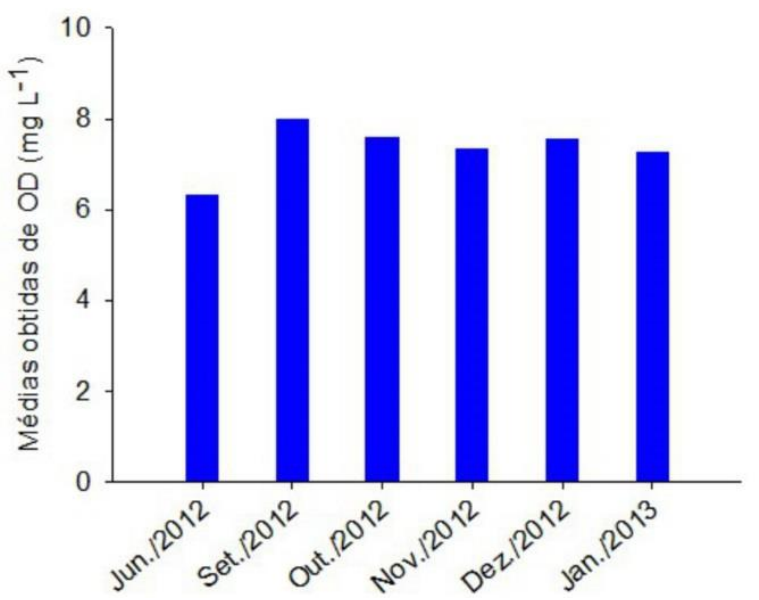

CE é a expressão numérica da capacidade de uma água conduzir a corrente elétrica, depende das concentrações iônicas e da temperatura e indica a quantidade de sais existentes na coluna d'água.

Os resultados obtidos para CE variaram de 32,90 a $47,63 \mu \mathrm{S} \mathrm{cm}^{-1}$ (Tabela 6), observandose as maiores médias nos meses de setembro (42,7 $\left.\mu \mathrm{S} \mathrm{cm} \mathrm{cm}^{-1}\right)$, outubro $\left(47,13 \mu \mathrm{S} \mathrm{cm}^{-1}\right)$ e novembro $\left(47,63 \mu \mathrm{S} \mathrm{cm}^{-1}\right)$, conforme Figura $7 \mathrm{a}$. 
Os valores elevados podem estar relacionados às atividades de preparo do solo, plantios, aplicações de insumos agrícolas e rochas da formação Vale do Rio do Peixe na região da bacia. Conforme Rocha et al. (2014), essas rochas são ricas em material carbonático, aumentando a condutividade na água após a dissolução. Além disso, o maior índice pluviométrico observado em novembro (Figura 5) pode ter favorecido o arraste de partículas de solos, matéria orgânica e outros materiais que tendem a elevar a CE. Valores superiores,

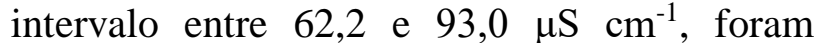
obtidos nas águas do Rio Jucu Braço Norte, bacia hidrográfica predominantemente agrícola (Terra et al., 2010).

Nos afluentes do reservatório da UHE Barra dos Coqueiros - GO, foi observada enorme discrepância entre os valores da $\mathrm{CE}$, variando entre 10,5 e $135,8 \mu \mathrm{S} \mathrm{cm}^{-1}$. Os autores ressaltam que os altos valores de $\mathrm{CE}$ são em decorrência dos fatores litológicos associados às rochas da formação Vale do Rio do Peixe e Marília (Rocha et al. 2014).

Os valores encontrados de SDT variaram de 15,20 a 22,50 $\mathrm{mg} \mathrm{L}^{-1}$ (Tabela 6), estando todos

(a)

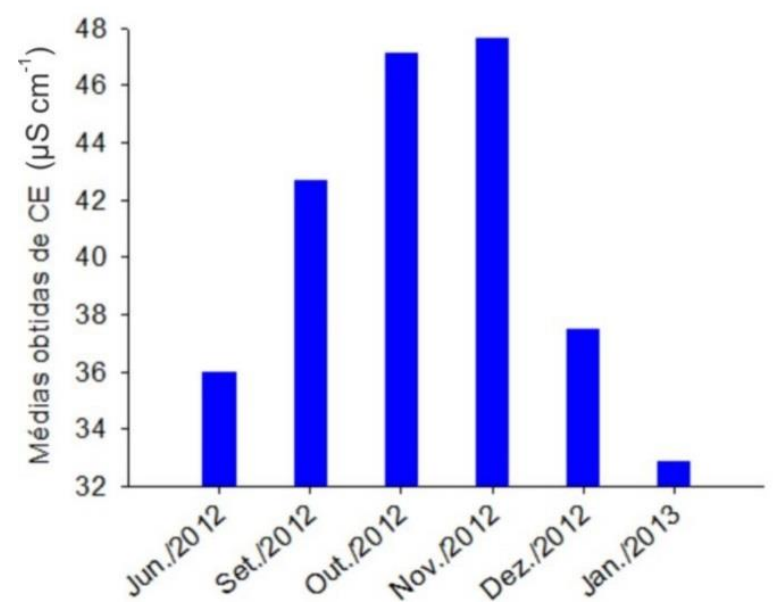

Figura 7. Gráfico com os valores mensais de condutividade elétrica (a) e sólidos dissolvidos totais (b) obtidos das águas do Ribeirão das Abóboras durante o período de ensaio. em conformidade com a Resolução CONAMA $357 / 05$ que especifica $500 \mathrm{mg} \mathrm{L}^{-1}$ como limite máximo de SDT em rios de classe 2. A Figura $7 \mathrm{~b}$ apresenta os valores de SDT, que podem estar relacionados com preparo do solo, plantio, aplicação de insumos agrícolas e altas precipitações, favorecendo o carreamento de sólidos e aumentando os valores de CE. Conforme Terra et al. (2010), valores altos de SDT podem estar relacionados à alta pluviosidade. Rocha et al. (2014) afirmam que aumentos nos valores de SDT estão relacionados à maior concentração de íons na água, possivelmente devido a precipitação na bacia, dissolução ou intemperização das rochas e solos da região, agravadas pelas atividades antrópicas no entorno. Nos estudos da qualidade da água do Ribeirão Piancó, em Anápolis - GO, Santos e Borges (2012) encontraram valores médios de $8,4 \mathrm{mg} \mathrm{L}^{-1}$ na época seca e de $11,6 \mathrm{mg} \mathrm{L}^{-1}$ na época chuvosa. Valores mais elevados que os obtidos no Ribeirão das Abóboras foram verificados na bacia do rio Jucu Braço Norte, entre 183,5 e $210,8 \mathrm{mg} \mathrm{L}^{-1}$ (Terra et al., 2010).

(b)

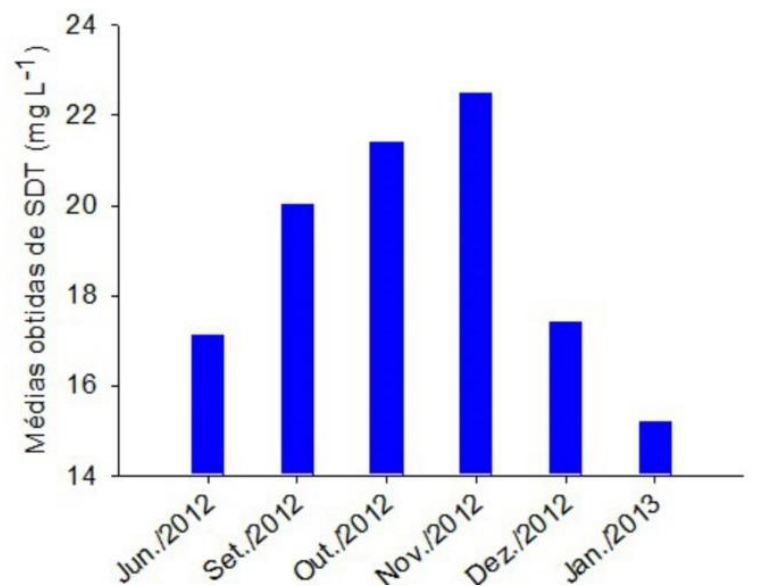

Tabela 7. Resultados da classificação de estado trófico no período de estudo.

\begin{tabular}{ccc}
\hline Mês & IET & Categoria \\
\hline Junho & 59,96 & Eutrófico \\
Setembro & 60,30 & Eutrófico \\
Outubro & 61,95 & Eutrófico \\
Novembro & 62,82 & Eutrófico \\
Dezembro & 62,18 & Eutrófico \\
Janeiro & 64,51 & Supereutrófico \\
\hline
\end{tabular}


A alteração nos valores de $\mathrm{pH}$ pode aumentar o efeito de substâncias químicas potencialmente tóxicas para os organismos aquáticos, possibilitando a precipitação de metais além de afetar o metabolismo de várias espécies (Paula, 2011). Por influenciar em diversos equilíbrios químicos que ocorrem naturalmente na água, o pH é uma variável importante no monitoramento de recursos hídricos (CETESB, 2016).

Os valores de $\mathrm{pH}$ variaram entre 6,60 a 7,81 (Tabela 6 e Figura 8a) e estão dentro do limite estabelecido pela Resolução CONAMA 357/2005 para águas de classe 2. Corroborando com os dados observados, Lima \& Santos (2012) obtiveram valores de $\mathrm{pH}$ variando entre 6,34 e 7,21 na bacia do Rio Claro.

Esteves (2011) afirma que, em geral, os corpos d'água continentais apresentam valores de $\mathrm{pH}$ entre 6,0 e 8,5, mas valores extremos são encontrados em regiões com características peculiares. Em lagos amazônicos, por exemplo, que apresentam solos ácidos, ou em ecossistemas de águas escuras, ricos em substâncias húmicas, o $\mathrm{pH}$ apresenta valor ácido, em torno de 5,0.

(a)

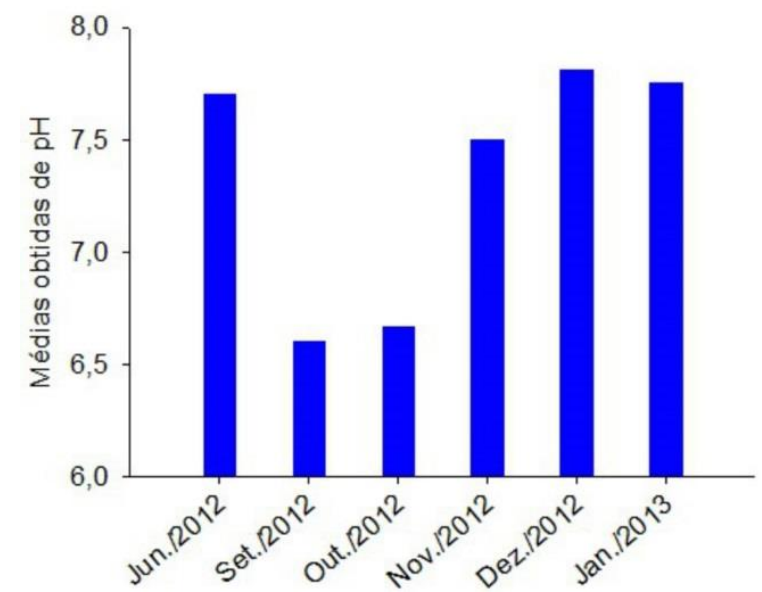

Figura 8. Gráfico com os valores mensais de $\mathrm{pH}$ (a) e turbidez (b) obtidos das águas do Ribeirão das Abóboras durante o período de ensaio.
Com o aumento da precipitação e, consequente, aumento dos sólidos em suspensão, ocorrem picos nos valores de turbidez, pois impedem o feixe de luz de penetrar na água (Arcova \& Cicco, 1999).

No presente trabalho foram observados valores de turbidez variando entre 7,85 e 57,8 UNT, abaixo do limite máximo de referência, que corresponde a 100 UNT (Tabela 6), sendo a maior média no mês de dezembro (Figura $8 b$ ).

Conforme Esteves (2011), os principais fatores responsáveis pela turbidez da água, bem como a dispersão da radiação, são as partículas suspensas (como as bactérias, fitoplâncton, detritos orgânicos e inorgânicos) e em menor proporção os compostos dissolvidos.

Pimenta et al. (2009) encontraram índices bem acima de 100 UNT na bacia do rio São Tomaz - GO. Vasco et al. (2011) verificaram na sub-bacia do rio Poxim valores superiores aos limites estabelecidos pelo CONAMA para água doce classe 2, maiores que 157 UNT, sendo atribuídos aos sólidos em suspensão, provenientes dos processos erosivos, e desmatamentos.

(b)

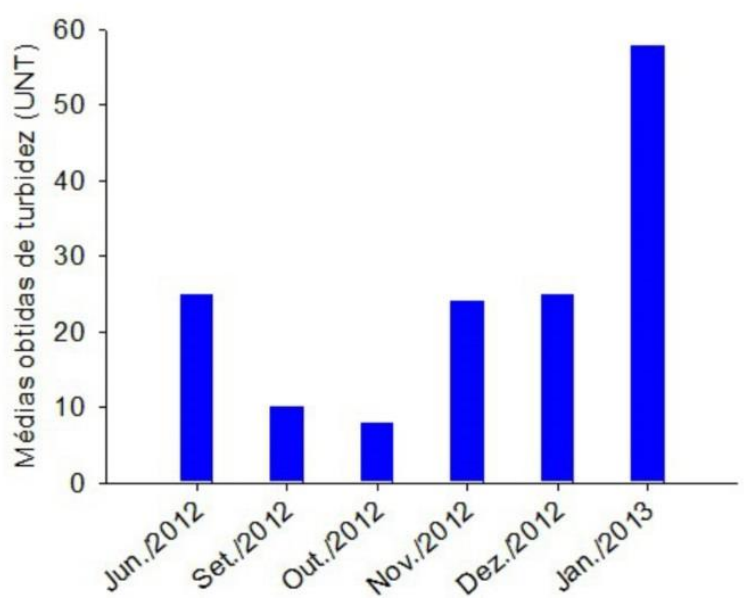

Sabe-se que a Resolução CONAMA $357 / 2005$ não apresenta limites quanto aos valores de DQO. Chapman \& Kimstach (1996) adotam como critério de qualificação de águas superficiais, não poluídas, um limite de DQO de $20 \mathrm{mg} \mathrm{L}^{-1}$.

Para a bacia em análise foi observado DQO variando entre 2,57 a $6,83 \mathrm{mg} \mathrm{L}^{-1}$ (Tabela 6 e
Figura 9a). As maiores concentrações foram observadas nos meses de dezembro de 2012 e janeiro de 2013, com 5,33 e 6,83 $\mathrm{mg} \mathrm{L}^{-1}$, respectivamente, o que pode estar relacionado ao carreamento de matéria orgânica para o corpo hídricos, lançamento de resíduos industriais ou das granjas. Segundo Vasco (2011), as variações da DQO pode ser 
consequência do comportamento hidrológico e do lançamento de efluentes domésticos, agrícolas e industriais.

Valores de DQO superiores aos obtidos no presente trabalho foram encontrados por Bregunce et al. (2011), os quais avaliaram a qualidade da água do Ribeirão dos Müller, microbacia urbanizada situada em Curitiba, Paraná, e observaram valores variando de 51 a $676 \mathrm{mg} \mathrm{L}^{-1}$, com valor médio de $250,82 \pm 186,48$ $\mathrm{mg} \mathrm{L}^{-1}$, sendo esse corpo de água caracterizado como impactado em decorrência de lançamento de esgoto doméstico e, possivelmente, de outro tipo de lançamento de água residuárias. Portanto, para os índices encontrados para esta variável, sugere-se que as águas do Ribeirão das Abóboras não apresentam quantidade alta de matéria orgânica no ponto amostral.

Os valorem médios de alumínio (Tabela 6 e Figura 9b) variaram de 0,02 a $0,08 \mathrm{mg} \mathrm{L}^{-1}$. Todos os valores expressos nos seis meses de monitoramento atenderam a Resolução vigente

(a)

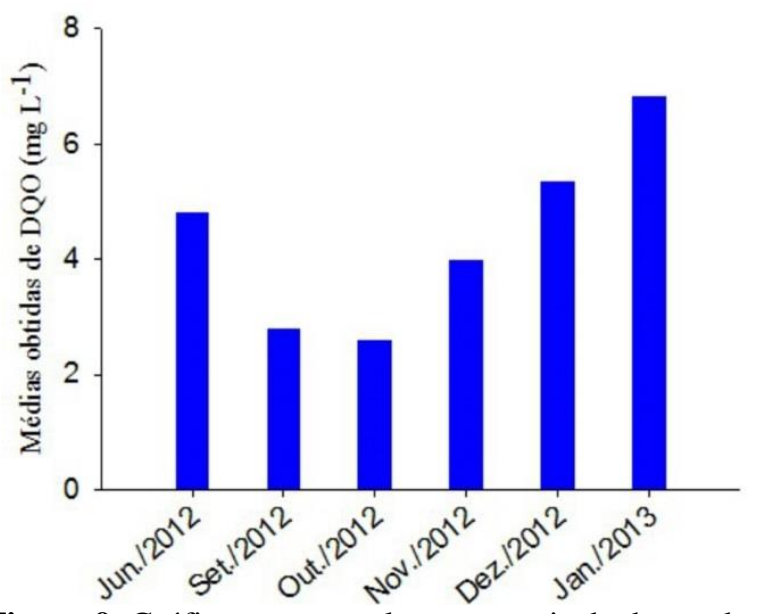

Figura 9. Gráfico com os valores mensais de demanda química de oxigênio (a) e alumínio (b) obtidos das águas do Ribeirão das Abóboras durante o período de ensaio. que define a concentração máxima de alumínio igual a $0,1 \mathrm{mg} \mathrm{L}^{-1}$ para corpos de água doce classe 2 .

Os menores valores de $\mathrm{Al}^{3+}$ foram encontrados nas amostras dos meses de setembro $\left(0,03 \mathrm{mg} \mathrm{L}^{-1}\right)$, outubro $\left(0,02 \mathrm{mg} \mathrm{L}^{-1}\right) \mathrm{e}$ novembro $\left(0,03 \mathrm{mg} \mathrm{L}^{-1}\right)$, período em que se verificam menores médias para temperatura, $\mathrm{pH}$, turbidez (baixos índices podem indicar menos íons e matéria orgânica na água) e DQO (medida indireta da concentração de matéria orgânica), Figura 6a, 8a, 8b e 9a. A CETESB (2016) relata que o alumínio pode ocorrer na água em diferentes formas e é influenciado pela temperatura, $\mathrm{pH}$, matéria orgânica, turbidez e outros. É importante ressaltar que a Portaria 2914/11 do Ministério da Saúde estabelece um valor máximo permitido de $0,2 \mathrm{mg} \mathrm{L}^{-1}$ de alumínio como padrão de aceitação para água de consumo humano (Brasil, 2011). Portanto, as águas da bacia em estudo estão dentro do limite aceitável.

(b)

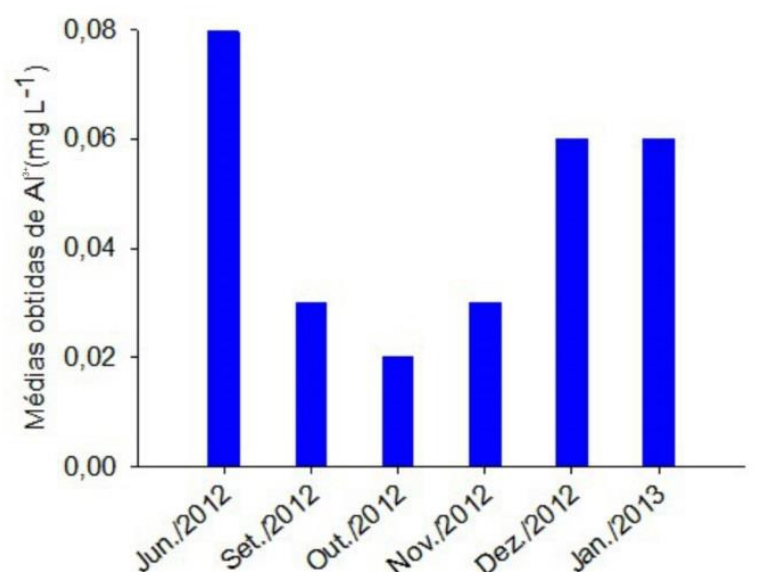

Carvalho (2011) afirma que o nitrato na água pode provocar uma doença ao ser humano conhecida como metemoglobinemia, e que as causas do aumento desse nutriente na água são o lançamento de esgotos domésticos e industriais, fertilizantes, excrementos de animais entre outros.

Os níveis de nitrato encontrados variaram de 0,21 a $2,35 \mathrm{mg} \mathrm{L}^{-1}$ com a maior média obtida em novembro (Figura 10a), provavelmente resultante da aplicação de adubos nitrogenados, e nos meses com maiores precipitações pode ocorrer o carreamento para o Ribeirão das
Abóboras. Os resultados encontrados atenderam ao limite máximo de referência, 10 $\mathrm{mg} \mathrm{L}^{-1}$ (Tabela 6). Outra fonte que contribui para o aporte de nitrogênio orgânico e amoniacal na água é o escoamento das águas pluviais pelos solos fertilizados (CETESB, 2016).

Borsatto et al. (2010) analisaram a água dos rios Tocantins e Cacau, bacias com uso e ocupação diversos e predominantemente agrícolas, no trecho da construção da Ponte da Amizade, que liga Imperatriz (MA) à cidade de São Miguel (TO), e também encontraram níveis 
de nitrato dentro dos valores recomendados pela legislação, onde as médias variaram de 1,01 a $1,28 \mathrm{mg} \mathrm{L}^{-1}$ no Rio Tocantins e 3,78 a 3,24 $\mathrm{mg} \mathrm{L}^{-1}$ no Rio Cacau. Porém, ao monitorar a qualidade da água em mananciais pertencentes à bacia hidrográfica do Tietê, dotada de uso múltiplo, em Botucatu - SP, Tofoli (2010) obteve concentrações de nitrato variando de 0,23 a $29,25 \mathrm{mg} \mathrm{L}^{-1}$. Este autor relata que os resultados elevados são, provavelmente, em consequência do uso de defensivos agrícolas na bacia.

O elemento fósforo é uma variável de qualidade da água extremamente importante, uma vez que sua presença em grandes concentrações em corpos hídricos pode levar a um processo de eutrofização (Carvalho, 2011).

Os teores de FT encontrados variaram de 0,15 a $0,36 \mathrm{mg} \mathrm{L}^{-1}$, estando todos os valores acima do limite de referência de $0,10 \mathrm{mg} \mathrm{L}^{-1}$ exigido pelo CONAMA (Tabela 6). Esses níveis elevados de FT podem ter sido provocados pela presença, à montante do ponto amostral, de diversas agroindústrias (frigorífico, fábrica de ração e fertilizantes, entre outros), instalações de granjas de suinocultura e avicultura, além da aplicação de fertilizantes

(a)

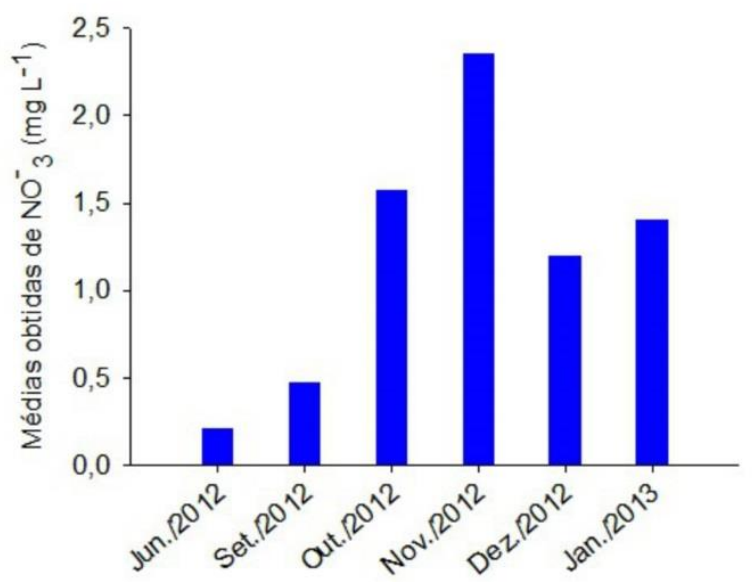

Figura 10. Gráficos com os valores mensais de nitrato $\left(\mathrm{NO}_{3}^{-}\right)$e fósforo total $(\mathrm{FT})$ obtidos das águas do Ribeirão das Abóboras durante o período de ensaio.

Na avaliação das águas do Rio São Tomaz, no sudoeste Goiano, no período chuvoso, por Pimenta et al. (2009), todos os resultados obtidos para fósforo total estão acima de 0,10 $\mathrm{mg} \mathrm{L^{-1 }}$.

Nos estudos da qualidade da água em uma microbacia hidrográfica do Rio Piracicaba - fosfatados para produção agrícola. Os maiores valores de fósforo foram observados nos meses de outubro de 2012 a janeiro de 2013 (Figura 10b), no período chuvoso (Figura 5), provocando fortes enxurradas e, consequentemente, carreando fósforo para o curso d'água.

A predominância de área agrícola $(46,46 \%$; Tabela 1) com aplicações de insumos agrícolas nas lavouras de soja e milho e as intensas precipitações ocorridas formam um conjunto favorável ao carreamento de fósforo para o ribeirão em questão.

Sabe-se que alguns efluentes industriais, como os advindos de indústrias de fertilizantes, pesticidas, químicas em geral, conservas alimentícias, abatedouros, frigoríficos e laticínios, apresentam fósforo em quantidades excessivas, provocando excesso de fósforo em águas naturais a partir da drenagem em áreas agrícolas (Carvalho, 2011; Paula, 2011; CETESB, 2016).

A aplicação de fertilizantes e pesticidas no solo aumenta a vulnerabilidade dos corpos de água e os custos do tratamento das águas (Tundisi et al., 2008).

(b)

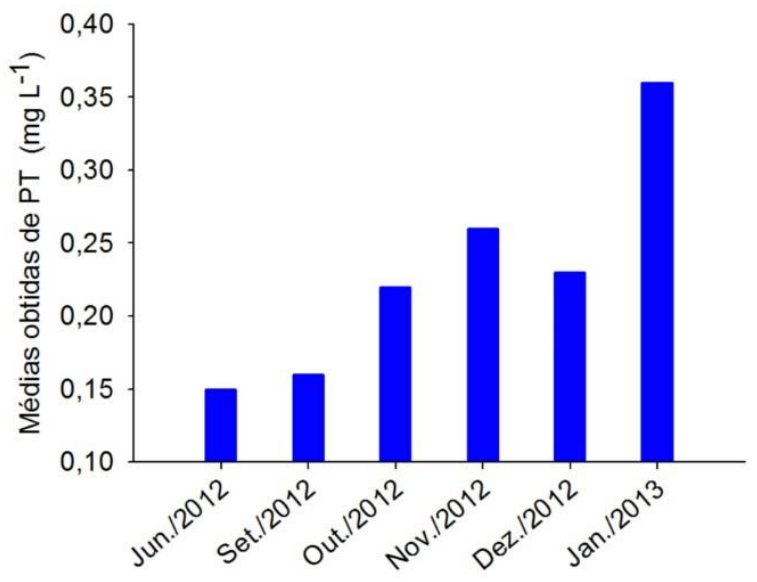

SP, ocupada principalmente por agricultura e outras pequenas partes por indústrias, Lucas et al., (2010) encontraram valores de fósforo total acima do limite máximo estabelecido pela Resolução CONAMA 357/05 para corpos de água doce classe 2 , tanto no período seco quanto úmido. 
Em pesquisa realizada por Medeiros et al. (2009), no Córrego do Recanto, Americana SP, em uma microbacia caracterizada por apresentar pequena parte urbanizada e a grande maioria como rural, foram obtidos níveis de fósforo extremamente elevados ao longo do período de estudo, com valores entre 1,5 e 5,0 mg L $\mathrm{L}^{-1}$, demonstrando um quadro de degradação na qualidade da água, provavelmente devido a lançamentos de resíduos de origem doméstica.

Segundo Tundisi \& Matsumura-Tundisi (2008), Vasconcelos (2009) e Esteves (2011), as características geológicas e pedológicas de uma bacia hidrográfica podem causar alterações na qualidade da água. Entretanto, as

(a)

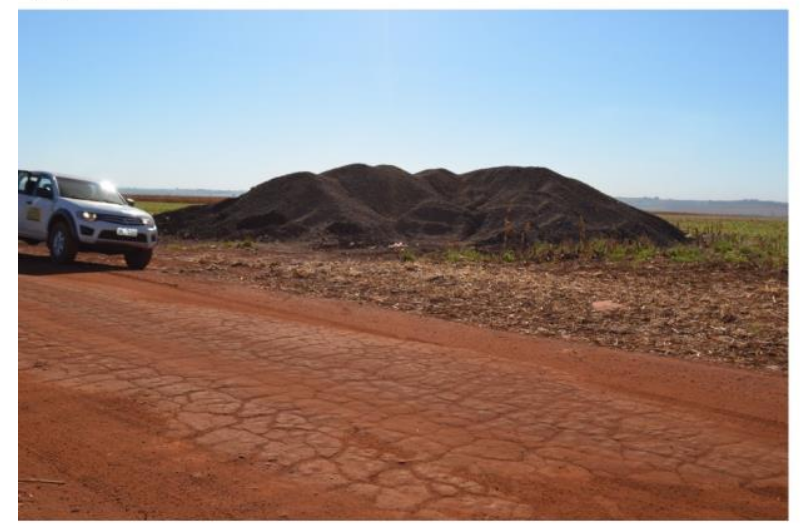

(c)

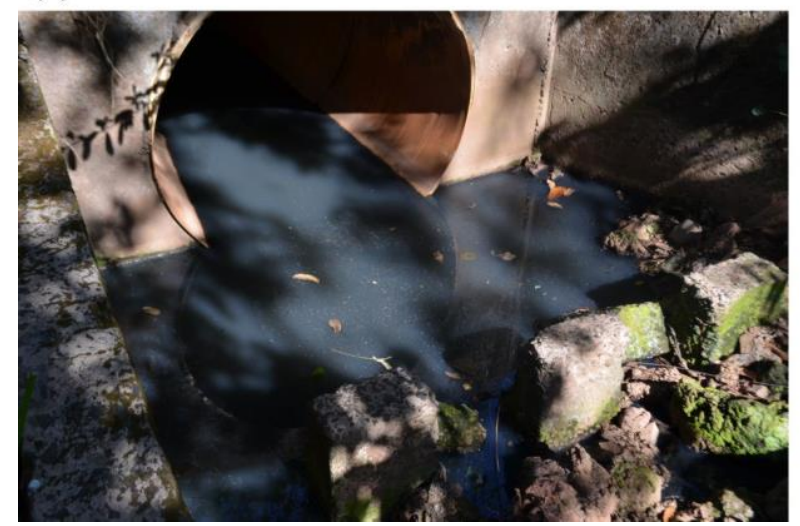

características das rochas e solos da bacia hidrográfica em estudo não são favoráveis a alterações naturais na qualidade da água.

Durante o período deste estudo, foram observados na bacia do Ribeirão das Abóboras, a montante do ponto amostral, resíduos oriundos das granjas com presença de chorume dispostos na superfície do solo (Figura 11a e Figura 11b) e resíduos industriais sem tratamento sendo lançados no ribeirão através de canais construídos para drenar águas da chuva de área industrial pavimentada (Figura 11c e Figura 11d). Estas observações reforçam que os maiores valores de CE, SDT, turbidez, DQO, $\mathrm{Al}^{3+}, \mathrm{NO}_{3}^{-}$e $\mathrm{PT}$ podem ser devido à ação antrópica.

(b)

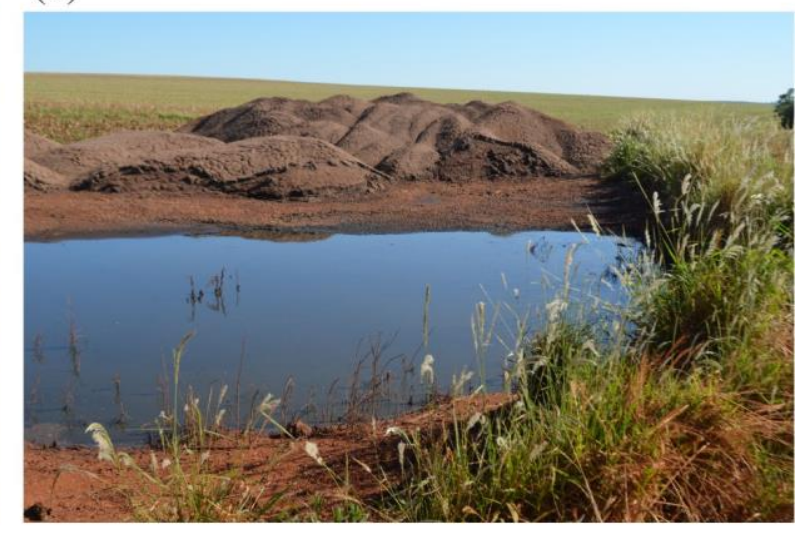

(a)

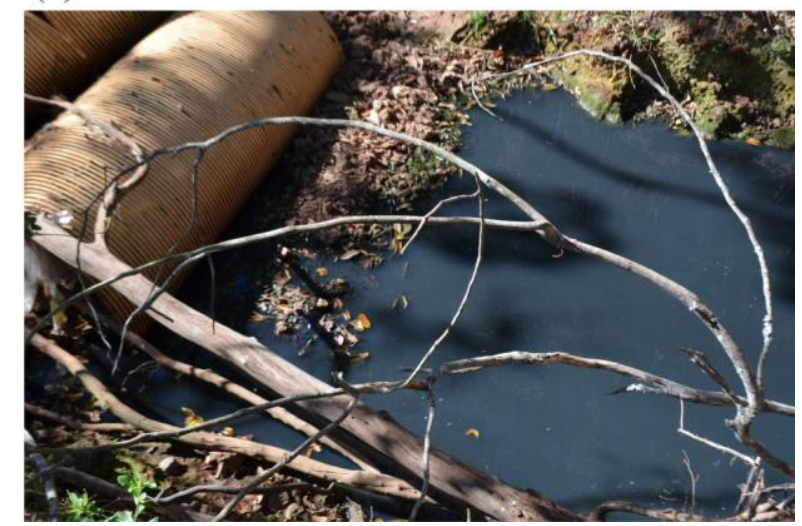

Figura 11. Fontes de matéria orgânica/resíduos observadas na área de contribuição do ponto amostral.

\section{Índice do estado trófico (IET)}

A CETESB (2016) destaca que o fósforo, assim como o nitrogênio, constitui um dos principais nutrientes utilizados nos processos biológicos, ou seja, é tido como um macronutriente por ser exigido também em grandes quantidades pelas células, e, por ser nutriente para processos biológicos, o excesso de fósforo em esgotos sanitários e efluentes industriais conduz a processos de eutrofização das águas naturais.

A Tabela 7 apresenta a classificação dos valores de IET, sendo 59,96 para o mês de junho, 60,30 para setembro, 61,95 para outubro, 62,82 para novembro, 62,18 para dezembro e 64,51 para janeiro. Conforme a classificação de Lamparelli (2004), corpos de água que apresentam nível de IET maior que 59 e igual 
ou menor que $63(59<$ IET $\leq 63)$ são eutróficos. IET maior que 63 e igual ou menor que $67(63<$ IET $\leq 67)$ são supereutróficos. Assim, a água do Ribeirão das Abóboras foi classificada como Eutrófico entre junho e dezembro e Supereutrófico no mês de janeiro.

Os maiores valores de IET (Tabela 7) coincidem com o período chuvoso (Figura 5) e de intensas práticas agrícolas, como preparo do solo e altas aplicações de fertilizantes NPK nas lavouras de soja e milho, situação favorável ao carreamento de fósforo.

Tundisi (2008) afirma que a eutrofização de lagos, represas e rios é uma das consequências dos usos excessivos de fertilizantes na agricultura. $\mathrm{O}$ autor ressalta que o efeito combinado da aplicação excessiva de nutrientes com alterações de drenagem pode rapidamente aumentar os índices de estado trófico, incluindo as águas subterrâneas.

Para a Agência Nacional de Água (Brasil, 2011), do ponto de vista ecológico, os ambientes eutróficos possuem alta produtividade considerando as condições ambientais e são influenciados pelas atividades antrópicas como, por exemplo, lançamento inadequado do esgoto, entrada de nutrientes provenientes de fontes difusas como agricultura e pecuária, que ocorrem em seu entorno.
A eutrofização das águas continentais pode ser um processo natural, porém, o descarte de efluentes domésticos e/ou industriais e lavagem de solos agrícolas contendo nutrientes (matéria orgânica) aceleram o processo, causando a chamada eutrofização artificial ou antrópica. Ambientes enriquecidos são denominados ambientes eutróficos (Brasil, 2011).

Esteves (2008) afirma que eutrofização artificial pode levar um corpo d'água a se tornar inaproveitável como fonte para abastecimento doméstico, irrigação, geração de energia hidrelétrica, produção de pescado ou área de lazer. Silva et al. (2014) avaliaram a qualidade de águas dos rios Anil e Bacanga, São Luís MA, rios caracterizados por possuírem entornos com povoamento e atividades rurais, obtiveram IET com variação de supereutrófico a hipereutrófico para o primeiro rio, e de mesotrófico a supereutrófico, para o segundo. $\mathrm{Na}$ determinação do índice de estado trófico, para fósforo em pontos do rio pomba, Farage et al. (2010) obtiveram valores de IET com tendência à hipereutrofização. As maiores concentrações de fósforo nas águas foram associadas a efluentes domésticos e industriais, destacam os autores.

\section{CONCLUSÃO}

Os resultados em todo o período de avaliação da qualidade das águas do Ribeirão das Abóboras para turbidez, oxigênio dissolvido, $\mathrm{pH}$, sólidos dissolvidos totais, nitrato e alumínio se encontram dentro dos limites estabelecidos pela Resolução CONAMA no 357 de 2005 para águas doces classe 2. A temperatura, demanda química de oxigênio e condutividade elétrica apresentaramse dentro de valores encontrados em águas doces não impactadas. Todos os teores médios de fósforo total estavam acima do limite permitido. Conforme os índices de estado trófico, a água foi classificada como Eutrófico entre junho e dezembro e Supereutrófico no mês de janeiro. Os níveis de fósforo e os índices do estado trófico demonstram que ações antrópicas podem estar causando impactos negativos na principal fonte de água que abastece a população urbana rio-verdense e que medidas de planejamento e gestão no uso da terra devem ser tomadas objetivando melhorar a qualidade ambiental e de vida.

Os meses do período chuvoso, que coincidem com a época de práticas agrícolas intensas, são os que apresentam maiores teores de fósforo total e nitrato, provavelmente carreados para os cursos d'água pela erosão laminar.

Por ter sido um trabalho com análises realizadas predominantemente no período chuvoso, há necessidade de novos estudos que caracterizem as águas do Ribeirão das Abóboras com número significativo de amostragens também no período de estiagem. 


\section{REFERÊNCIAS BIBLIOGRÁFICAS}

1. AGÊNCIA NACIONAL DE ÁGUAS. Conjuntura dos recursos hídricos: informe 2014. Brasília: ANA, 2015. $107 \mathrm{p}$.

2. APHA (American Public Health Association), 2005. Standard Methods for the Examination of Water and Waste Water, 22th ed. APHA-AWWA-WPCF, Washington, DC.

3. ARCOVA, F.C.S.; CICCO, V. 1999. Qualidade da água de microbacias com diferentes usos do solo na região de Cunha, estado de São Paulo. Scientia Forestalis, n. 56, p. 125134, 1999.

4. BORSATTO, J. C. L.; BORSATTO, M. V.; ORLANDO, J. F. F.; SILVA, M. F.; SILVA, D. G. K. C. Análise da qualidade da água nos Rios Tocantins e Cacau no trecho da construção da Ponte da Amizade. Engenharia Ambiental, v. 7, n. 2, p. 163-177, 2010.

5. BDMEP (Banco de Dados Meteorológicos para Ensino e Pesquisa). Disponível em: http://www.inmet.gov.br/projetos/rede/pesquisa/. Acesso em: 8 set. 2014.

6. BRASIL. Ministério do Planejamento, Orçamento e Gestão. Instituto Brasileiro de Geografia e Estatística - IBGE. Manual Técnico de Uso da Terra, $3^{\circ}$ ed. Rio de Janeiro, 2013.

$7 . \quad$ Agência Nacional de Água-ANA. Resolução 724/2011. Estabelece procedimentos padronizados para a coleta e preservação de amostras de águas superficiais para fins de monitoramento da qualidade dos recursos hídricos, no âmbito do Programa Nacional de Avaliação da Qualidade das Águas (PNQA). Diário Oficial [da] República Federativa do Brasil, Brasília, 19 de outubro de 2011.

8 Conselho Nacional do Meio Ambiente CONAMA. Resolução CONAMA $n^{\circ} 357$, alterada pela Resolução 410/2009 e pela 430/2011. Dispõe sobre a classificação dos corpos de água e diretrizes ambientais para o seu enquadramento, bem como estabelece as condições e padrões de lançamento de efluentes, e dá outras providências. Diário Oficial [da] República Federativa do Brasil, Brasília, 17 de mar. de 2005.

9

Lei $\mathrm{N}^{\circ}$ 9.433, de 8 de janeiro de 1997. Institui a Política Nacional de Recursos Hídricos, cria o Sistema Nacional de Gerenciamento de Recursos Hídricos, regulamenta o inciso XIX do art. 21 da Constituição Federal, e altera o art. $1^{\circ}$ da Lei $\mathrm{N}^{\circ} 8.001$, de 13 de março de 1990 , que modificou a Lei $\mathrm{n}^{\mathrm{o}} 7.990$, de 28 de dezembro de 1989. Diário Oficial [da] República Federativa do Brasil, Brasília, 9 jan. 1997.

10. BREGUNCE, D. T.; JORDAN, E. N.; DZIEDZIC, M.; MARANHO, L. T.; CUBAS, S. A. Avaliação da Qualidade da Água do Ribeirão dos Müller, Curitiba-PR. RBRH: Revista brasileira de recursos hídricos, v. 16 n.3, p. 39-47, 2011.

11. CARVALHO, A. A. A. A. Avaliação das áreas de preservação permanente de cursos d'água na área de proteção de manancial do córrego Quinze, Distrito Federal. Brasília, 2011. 145 f. Dissertações (Mestrado em Geociências Aplicadas) - Instituto de Geociências Aplicadas, Universidade de Brasília.

12. CETESB (Companhia de Tecnologia de Saneamento Ambiental de São Paulo). Publicações e Relatórios. Disponível em: http://aguasinteriores.cetesb.sp.gov.br/publicacoes-erelatorios/. Acesso em: 20 jun. 2016.

13. COUTO, T. C.; FARIA, D. C.; NAVAL, L. P. Análise das variáveis físico-químicas da água do rio Javaés, Ilha do Bananal, entorno do Parque Nacional do Araguaia, Tocantins Brasil. In: CONGRESO INTERAMERICANO DE INGENRÍA SANITARIA Y AMBIENTAL, PUNTA DEL LESTE URUGUAI, Montevideo. 30, 2006. Anais... Sección Uruguay: AIDIS, 2006. 30, 2006. Disponível em: http://www.bvsde.paho.org/bvsaidis/uruguay30/BR08506_CO UTO.pdf. Acesso em: 21 jul. 2015.
14. CHAPMAN, D. \& KIMSTACH, V. Selection of water quality variables. In: CHAPMAN, D. (Ed.) Water quality assessment: a guide to the use of biota, sediments and water in environmental monitoring. Londres: UNESCO/ WHO/UNEP, Cap. 3, 60 p, 1996. Disponível em: http://www.who.int/water_sanitation_health/resources/wqa/en/. Acesso em: 21 jul. 2015.

15. ESTEVES, F. A. Fundamentos de Limnologia. $3^{\mathrm{a}}$ ed. Rio de Janeiro: Interciência, 2011, 826 p.

16. ESTEVES, F. Grandes temas em biologia. $2^{\mathrm{a}}$ ed. Rio de Janeiro: Fundação CECIERJ, 2008, 252 p.

17. FARAGE, J. A. P.; MATOS, A. T.; SILVA, D. D.; BORGES, A. C. Determinação do índice de estado trófico para fósforo em pontos do Rio Pomba. Engenharia na Agricultura, v.18 n.4, p. 322-329, 2010.

18. FERREIRA, W. S. Cultivo do milho e da soja em sucessão as culturas de safrinha em Rio Verde-GO. Rio Verde - GO, 2010. 67 f. Dissertação (Mestrado em Produção Vegetal). Universidade de Rio Verde.

19. GARCIA, A. V.; OLIVEIRA, E. C. A.; SILVA, G. P.; COSTA, P. P.; OLIVEIRA, L. A. Disponibilidade hídrica e volume de água outorgado na microbacia do Ribeirão das Abóboras, município de Rio Verde, estado de Goiás. Caminhos de Geografia, v.8, n. 22, p. 97-106, 2007. Disponível em: http://www.seer.ufu.br/index.php/caminhosdegeografia/article/ viewFile/15555/8804. Acesso em: 21 jul. 2015.

20. IBGE - Instituto Brasileiro de Geografia e Estatística. (2010). Censo demográfico 2010. Disponível em: http://www.cidades.ibge.gov.br/xtras/perfil.php?lang=\&codmu $\mathrm{n}=521880$ \&search=goias|rio-verde. Acesso em: 19 jul. 2015.

21. . (2014). Censo demográfico 2014. Disponível em:

http://www.cidades.ibge.gov.br/xtras/perfil.php?lang=\&codmu $\mathrm{n}=521880 \&$ search=goias|rio-verde. Acesso em: 20 jul. 2015.

22. LAMPARELLI, M. C. Grau de trofia em corpos d' água do Estado de São Paulo: avaliação dos métodos de monitoramento. São Paulo, 2004. 235 f. Tese (Doutorado em Ecologia Aplicada). Universidade de São Paulo.

23. LIMA, A. M. \& SANTOS, F. F. Análise das propriedades físico-químicas e de metais potencialmente tóxicos na água do Rio Claro, próximo à cidade de Jataí - GO. Ciências Exatas e Naturais, v. 14, n. 2, p. 239-255, 2012.

24. LUCAS, A. A. T.; FOLEGATTI, M. V.; DUARTE, S. N. Qualidade da água em uma microbacia hidrográfica do Rio Piracicaba, SP. Revista Brasileira de Engenharia Agrícola e Ambiental, v.14, n.9, p.937-943, 2010.

25. MEDEIROS, G. A.; ARCHANJO, P.; SIMIONATO, R.; REIS, F. A. G. V. Diagnóstico da qualidade da água na microbacia do córrego Recanto, em Americana, no estado de São Paulo. Geociências, v. 28, n. 2, p. 181-191, 2009.

26. PAULA, L. M. Avaliação da qualidade da água e autodepuração do rio Jordão, Araguari (MG). Uberlândia, 2011. 177 p. Dissertação (Mestrado em Engenharia Civil) Universidade Federal de Uberlândia.

27. PEEL, M. C., Finlayson, B. L., McMahon, T. A. Updated world map of the Köppen-Geiger climate classification. Hydrol. Earth Syst. Sc., v. 11, p. 1633-1644, 2007.

28. PIMENTA, S. M.; PEÑA, A. P.; GOMES, P. S. Aplicação de métodos físicos, químicos e biológicos na avaliação da qualidade das águas em áreas de aproveitamento hidroelétrico da bacia do Rio São Tomaz, município de Rio Verde - Goiás. Sociedade \& Natureza, v. 21, n. 3, p. 393-412, 2009.

29. PINTO, A. L.; OLIVEIRA, G. H.; PEREIRA, G. A. Avaliação da eficiência da utilização do oxigênio dissolvido 
como principal indicador da qualidade das águas superficiais da bacia do córrego Bom Jardim, Brasilândia, MS. GEOMAE, v.1, n.1 p. 69-82, 2010.

30. RODRIGUES, S.R.; BUSCHINELLI, C.C.A.; SANTANA, D.P.; SILVA, A.G.; PASTRELLO, B.M.C. Avaliação ambiental de práticas de manejo sítio específico aplicadas à produção de grãos na região de Rio Verde (GO). Revista Brasileira de Agrociência, v. 14, n. 3-4, p. 58-66, 2008.

31. ROCHA, H. M.; CABRAL, J. B. P.; BRAGA, C. C. Avaliação Espaço -Temporal das Águas dos Afluentes do Reservatório da UHE Barra dos Coqueiros/Goiás. Revista Brasileira de Recursos Hídricos, v. 19 n. 1, p. 131-142, 2014. 32. SANTOS, A. L. F. \& BORGES, L. O. S. Qualidade da água do Ribeirão Piancó, GO e suas implicações ambientais. Scientia Plena, v. 8, n. 5, 2012.

33. SIEG (Sistema Estadual de Geoinformação de Goiás). Download de Arquivos SIG (Shapefile). Disponível em: http://www.sieg.go.gov.br/. Acesso em: 01 jul. 2016.

34. SILVA, E. C.; COSTA, W.; MARQUES, M. B.; SILVA, N. C.; COSTA, R. P. Um indicativo da relação entre as atividades humanas e a contaminação das águas do Rio VerdePonta Grossa-PR. Ciências Exatas e da Terra, v.14, n. 3, p. 247-254, 2008.

35. SILVA, G. S.; SANTOS, E. A.; CORRÊA, L. B.; BRANDES, A. L. M.; MARQUES, E. P.; SOUSA, E. R.; SILVA, G. S. Avaliação integrada da qualidade de águas superficiais: grau de trofia e proteção da vida aquática nos rios Anil e Bacanga, São Luís (MA). Engenharia Sanitária e Ambiental, v. 19, n. 3, p. 245-250, 2014.

36. TERRA, V. R.; PRATTE-SANTOS, R.; ALIPRANDI, R. B.; BARCELOS, F. F.; MARTINS, J. L. D.; AZEVEDO JR, R. R.; BARBIÉRI, R. S. Estudo limnológico visando avaliação da qualidade das águas do rio Jucu Braço Norte, ES. Natureza On Line, v. 8 n. 1, p. 8-13, 2010.

37. TOFOLI, L. A. Monitoramento da qualidade da água em mananciais pertencentes à bacia hidrográfica do Tietê - Botucatu, SP. Botucatu, 2010. 104 p. Dissertações (Mestrado em Agronomia) - Universidade Estadual Paulista.
Disponível em: http://hdl.handle.net/11449/90487. Acesso em: 21 jul. 2015.

38. TORRES, J. L. R. \& FABIAN, A. J. Levantamento Topográfico e Caracterização da paisagem para planejamento conservacionista em microbacia hidrográfica de Uberaba-MG. Caminhos de Geografia, v. 6, n.19, p. 150-159, 2006. Disponível em: http://www.seer.ufu.br/index.php/caminhosdegeografia/article/ viewFile/15496/8775. Acesso em: 21 jul. 2015.

39. TUNDISI, J. G.; MATSUMURA-TUNDISI, T. Limnologia. São Paulo: Oficina de Textos, 2008. 631p.

40. TUNDISI, J. G.; MATSUMURA-TUNDISI, T.; PARESCHI, D. C.; LUZIA, A. P.; VON HAELING, P. H.; FROLLINI, E. H. A bacia hidrográfica do Tietê/Jacaré: estudo de caso em pesquisa e gerenciamento. Estudos Avançados, v. 22, n. 63 , p. $159-172,2008$

41. TUNDISI, J. G. Recursos hídricos no futuro: problemas e soluções. Estudos Avançados, v. 22, n. 63, p. 7$16,2008$.

42. USGS (United States Geological Survey). Earthexplorer. Disponível em: http://earthexplorer.usgs.gov. Acesso em: 20 jan. 2016.

43. VASCO, A. N.; BRITTO, F. B.; PEREIRA, A. P. S.; MÉLlO JÚNIOR, A. V.; GARCIA, C. A. B.; NOGUEIRA, L. C. Avaliação espacial e temporal da qualidade da água na subbacia do rio Poxim, Sergipe, Brasil. Ambiente \& Água, v. 6, n. 1, p. 118-130, 2011.

44. VASCONCELOS, F. M.; TUNDISI, G. J.; MATSUMURA-TUNDISI, T. Avaliação da qualidade de água. $1^{a}$ ed., Sociedade Mineira de Engenheiros Agrônomos, 322 p., 2009.

45. ZUMACH, R. Enquadramento de curso de água: rio Itajaí-Açu e seus principais afluentes em Blumenau. Florianópolis, 2003. 133 f. Dissertação (Mestrado em Engenharia Ambiental) - Universidade Federal de Santa Catarina.

Manuscrito recebido em: 07 de Janeiro de 2016 Revisado e Aceito em: 01 de Setembro de 2016 